\title{
Partial migration and effects of climate on migratory movements of sika deer in Kirigamine Highland, central Japan
}

\author{
Akiko Takii ${ }^{1 * *}$, Shigeyuki Izumiyama ${ }^{2}$ and Makoto Taguchi ${ }^{3}$ \\ ${ }^{1}$ Interdisciplinary Graduate School of Science and Technology, Shinshu University, 8304 Minami-Minowa, Kami-Ina, \\ Nagano 399-4598, Japan \\ ${ }^{2}$ Faculty of Agriculture, Shinshu University, Nagano 399-4598, Japan \\ ${ }^{3}$ Washigamine Hütte, Nagano 393-0000, Japan
}

\begin{abstract}
Studies on migration pattern of sika deer in Japan are limited. We captured 27 sika deer and identified movement for 24 deer (17 females and 7 males) from 2008 to 2011 in Kirigamine Highland, Nagano, central Japan. Four juvenile males dispersed from their original home range, and we documented migration pattern for 23 deer ( 17 females and 6 males), including 3 dispersed males. Deer exhibited partial migration, regardless of sex: $65 \%(n=15)$ of the deer were migratory, whereas $35 \%(n=8)$ were non-migratory. All but 1 of the migratory deer migrated between high-elevation summer range and low-elevation winter range. Mean migration distance was $9.9 \mathrm{~km}$ (range $=3.2$ $22.9 \mathrm{~km}$ ). Fidelity to summer home range was stronger than fidelity to winter home range. In order to determine the effect of climate on the onset of migration at Kigiramine Highland, we examined 39 seasonal movements during 4 migratory periods. Most of autumn migrations occurred before the snow depth reached $20 \mathrm{~cm}$. Spring migrations occurred after the daily temperatures $>0{ }^{\circ} \mathrm{C}$ persisted for more than 3 days, and during periods when either snow had completely disappeared or snow melted rapidly.
\end{abstract}

Key words: central Japan, Cervus nippon, dispersal, migration, partial migration.

It has been well documented that cervids in middle to high-latitude regions migrate seasonally between discrete summer and winter ranges (e.g., moose Alces alces: Ball et al. 2001; mule deer Odocoileus hemionus: Kufeld et al. 1989; Nicholson et al. 1997; white-tailed deer $O$. virginianus: Sabine et al. 2002; Brinkman et al. 2005; roe deer Capreolus capreolus: Mysterud 1999; Ramanzin et al. 2007; Cagnacci et al. 2011; red deer Cervus elaphus: Mysterud et al. 2011; sika deer C. nippon: Uno and Kaji 2000; Igota et al. 2004). The factors affecting migration differs by season. Autumn migration, a movement from summer to winter range, is mainly triggered by snow depth (e.g., Tierson et al. 1985; Sabine et al. 2002; Ramanzin et al. 2007) and low ambient temperatures (Nelson 1995). Meanwhile, spring migration, a movement from winter to summer range, is mainly triggered by increasing temperatures and snow melting (e.g., Sabine et al. 2002; Brinkman et al. 2005; Ramanzin et al. 2007). Spring migration in mountain ranges where deer often exhibit altitudinal migration (i.e. movement between high elevation summer range and low elevation winter range) has been exclusively explained by forage maturation hypothesis that plants at early phenological stages have higher quality as forage than the matured (Albon and Langvatn 1992; Hebblewhite et al. 2008; Mysterud et al. 2011).

In places where climatic conditions vary seasonally, partial migration, within-population migratory dimorphism that some individuals migrate while others remain resident in a single habitat (Dingle and Drake 2007), is also common among various deer species. Such mixed migration strategy has been explained by variability in winter weather, especially snow depth (Nicholson et al. 1997; Sabine et al. 2002; Brinkman et al. 2005), and variability in topography and climate (Cagnacci et al. 2011). In recent studies, Mysterud et al. (2011) showed that topographic diversity (i.e. areas with access to high elevation) and population density is important for determining migration of red deer population.

Seasonal movement patterns of sika deer in Japan vary

*To whom correspondence should be addressed. E-mail:10st413j@shinshu-u.ac.jp 
over climate and geographical areas (Yabe and Takatsuki 2009). Igota et al. (2009) also suggested that snow cover, bamboo grass (winter forage) and coniferous cover are important factors to determine migration pattern. In central to northern Japan, sika deer has been shown to exhibit migratory (Honma 1995; Izumiyama and Mochizuki 2008; Takii et al. 2012), non-migratory (Nagata 2005), and both migratory and non-migratory (Maruyama 1981; Takatsuki et al. 2000; Igota et al. 2004) behavior in a single study area. High fidelity to seasonal home range and migration route has also been reported (Sakuragi et al. 2004; Igota et al. 2004). However, there are only 2 studies in Hokkaido (Uno and Kaji 2000; Igota et al. 2004) and 1 study in Honshu (Maruyama 1981) that evaluated migration strategies of sika deer from $>10$ individual deer. Furthermore, although it will be important for evaluating the migration strategy as a common strategy used by all the deer in the population, migration strategy between males and females of sika deer has not been studied.

In snowy region of central to northern Japan, snow depth and/or winter forage has been shown to affect the seasonal migration of deer (Maruyama 1981; Takatsuki et al. 2000; Igota et al. 2004). Meanwhile, recent studies revealed human activities and winter forage are more likely to affect the autumn migration of deer in less snow region of central Japan (Kamei et al. 2010; Takii et al. 2012). Although some studies documented that sika deer avoid snow depth exceeding $50 \mathrm{~cm}$ (Maruyama 1981; Takatsuki 1992), studies on factors associated with the initiation of seasonal migration have been poorly studied due to its wide variety of topography and climate in mountain region of Japan. Moreover, few studies have been carried out on high-elevation ranges in central Japan (Izumiyama and Mochizuki 2008).

In this paper, we investigated the migration behavior of $>20$ sika deer with combining sex in an unstudied population of high-altitude Kirigamine Highland, central Japan. We captured the deer during spring and summer when deer were most abundant in Kirigamine Highland. The objectives of the present study were: (1) to determine migration patterns of sika deer in Kirigamine Highland; (2) to examine fidelity to the seasonal home range; (3) to evaluate the effects of climate on timing of migration. Given that we captured the deer in high-altitude Kirigamine Highland where snow is relatively deep and topography is variable, we hypothesized that deer would exhibit partial migration, and the seasonal migration would be affected by winter weather. We also hypothe- sized that there would be no sexual difference in migration strategy because previous study showed no difference in migratory behavior for both sexes in central Honshu (Honma 1995; Takii et al. 2012).

\section{Materials and methods}

\section{Study area}

We captured and released the deer that summered in the core study area, Kirigamine Highland, central Nagano, while we monitored the seasonal movements of the deer on a surrounding area (Fig. 1). Kirigamine Highland extends in and along the west of Mt. Kurumayama $\left(36^{\circ} 06^{\prime} \mathrm{N}, 138^{\circ} 11^{\prime} \mathrm{E}\right.$; $1,925 \mathrm{~m}$ a.s.l.) with elevations above ca. $1,500 \mathrm{~m}$. Although the topography is rolling above ca. 1,600 m, it is relatively steep with narrow valleys in lower elevations. At Washigamine Hütte (1,660 $\mathrm{m}$ a.s.1.), which is located at the west of Yashimagahara Marsh, mean annual temperature was $5.9^{\circ} \mathrm{C}$, mean annual precipitation excluding snow was $1,328 \mathrm{~mm}$, and mean maximum snow depth was $75.2 \mathrm{~cm}$ for 1985-2007 (Hosoda and Taguchi 2009).

Kirigamine Highland is characterized by large area of secondary grasslands, dominated by Calamagrostis longiseta and Miscanthus sinensis (Nishimura et al. 1997). The grasslands occur from elevations above ca. $1,500 \mathrm{~m}$, and $>80 \%$ of vegetation is covered by grasslands above 1,700 $\mathrm{m}$ a.s.l. (Ozeki et al. 2006). The grasslands are surrounded by deciduous broad-leaved forests (dominated by Quercus crispula), evergreen coniferous forests (dominated by Abies homolepis), and Larix caempferi plantations with Sasa spp. as understory (Suzuki and Yano 1981). East end of Kirigamine Highland is contiguous to Yatsugatake Mountains, which extends north to south over $30 \mathrm{~km}$, with elevations ranging from $680 \mathrm{~m}$ to $2,899 \mathrm{~m}$. Most of the area between 1,100 2,000 $\mathrm{m}$ a.s.l. is covered by L. caempferi plantations, and the area below $1,100 \mathrm{~m}$ a.s.l. is covered by cultivated lands and small villages (Ministry of the Environment 1997).

Although sika deer was not common in Kirigamine until the early-1990s, spotlight counts conducted between 2004 and 2009 revealed that the number of deer per observation increased from ca. 20 to 65 (Kishimoto et al. 2010). On the contrary, sika deer was common in the surrounding areas of Kirigamine, particularly in Yatsugatake Mountains (mainly below 2,000 m a.s.l.; Suwa Educational Association 1981). Although large area of Kirigamine Highland (ca. $>1,600 \mathrm{~m}$ a.s.l.) is 
designated as wildlife protection area, where hunting is prohibited generally, hunting is permitted in the surrounding area from 15 November to 15 February (only trap hunting is permitted until $15 \mathrm{March}$ ).

\section{Deer capture}

We captured 23 deer (15 females and 8 males, including 1 female fawn [i.e. $<12$-month-old] and 4 male fawns) during April-July 2008, and 4 deer (3 females and 1 male) during May-August 2010 in Kirigamine Highland using dart-gun, mixture of Ketamine-HCL (200 mg) and Xylazine-HCL (200 mg) as a tranquilizer. We captured most deer at elevations above $1,500 \mathrm{~m}$. Deer were aged from tooth replacement and tooth wear. We fitted 20 deer with VHF collar (Advanced Telemetry Systems, Isanti, Minnesota, USA) and 7 deer with GPS collar (Tellus 5H1D, Followit AB, Lindesburg, Sweden). Three deer captured during 2008 were collared with both VHF and GPS collars to monitor the deer for longer period. Animal capture and handling followed the policies and guidelines provided by the Nagano Prefecture and the Mammalogical Society of Japan.

During May 2008 and July 2010, we triangulated VHF collared deer locations every 3-10 days using a handheld 3-element Yagi antenna and portable receiver (YAESU FT817, YAESU MUSEN, Tokyo, Japan). We located most of the VHF collared deer during the day using more than 3 telemetry bearings. Mean location error from known location was $97 \pm 60 \mathrm{~m}(n=13)$. Due to the different study objectives, GPS collar was scheduled to obtain a location every 15 minutes to 3 hours and to release within 365-730 days.

\section{Data analysis}

We examined the seasonal movements of the deer with $\geq 8$ months of tracking. We defined the deer migratory with non-overlapping winter and summer home ranges. We calculated migration distance as straight-line distance between the center of activity of the seasonal home range (i.e. mean longitude and latitude of the deer locations: Hayne 1949). In case of deer that wintered in 2 different areas, we used the area with longer duration of stay for analysis. We defined autumn migration as a movement from summer to winter home range, and spring migration as a movement from winter to summer home range. To estimate the approximate date of departure and arrival at Kirigamine Highland for the VHF collared deer, we calculated the median date of the last and the first day observed in the separate seasonal home ranges. We defined the deer non-migratory if the deer had overlapping summer and winter home range. We defined the deer dispersers if the fawns moved from natal home range and formed a non-overlapping home range. We calculated dispersal distance as straight-line distance between the center of activity of the predispersal and postdispersal home range. We examined the seasonal movements of the dispersed deer from postdispersal tracking data. Only the dispersed deer with $\geq 8$ months of tracking after dispersal was classified into migratory or non-migratory deer. We compared the proportion of migratory male and female by Fisher's exact test. We used Mann-Whitney $U$ tests to compare the migration distance between male and female.

We evaluated the elevation of center of activity for each seasonal home range using 10-meter digital elevation model (DEM) (Fundamental Geospatial Data: National Land Agency, Geospatial Information Authority of Japan, Tokyo) and Arc View Spatial Analyst software (ESRI 1996). We compared the elevation between summer and winter home range by Wilcoxon singed rank test. We used Mann-Whitney $U$ tests to compare the elevation of summer and winter home range between male and female, and to compare the elevation of summer home range between migratory and non-migratory deer. To examine the overlapping of non-migratory and migratory deer's summer home range, we counted the number of migratory deer which location points were inside each non-migratory deer's summer home range (delineated by minimum convex polygon method).

To assess fidelities to the seasonal home range of the deer, we calculated the distances between the center of activity for successive summer/winter home range. For resident deer, we defined summer as April to November, and winter as December to March. We compared the distances between the center of activity in successive years between summer and winter by Mann-Whitney $U$ test. We used SPSS software package version 11.5 for all the statistical analyses. Data were presented as mean \pm standard deviation.

To obtain daily weather data in Kirigamine, we measured daily temperature and snow depth at Washigamine Hütte. Daily temperature $\left({ }^{\circ} \mathrm{C}\right)$ was calculated from averaging the minimum and maximum daily temperature, which we measured from the thermometer inside the instrument screen (Isuzu Type 10, Isuzu Seisakusho, Niigata, Japan). We measured snow depth $(\mathrm{cm})$ as a mean of 2 measure poles. 


\section{Results}

\section{Migration pattern}

Of the 27 captured sika deer, 3 deer died before we could identify the migration pattern. We identified movement for 24 deer (17 females and 7 males, including 1 juvenile [i.e. 12- to 23-month-old] female and 4 juvenile males) from 45,916 deer locations (VHF telemetry: 1,451; GPS telemetry: 44,465). Four juvenile males dispersed from their natal home range, and we were able to document migration pattern for 23 deer, including 3 dispersed males. Since 1 juvenile male dispersed to Kawakami Village, ca. $40 \mathrm{~km}$ from Kirigamine Highland, we excluded this deer from the seasonal elevation analysis. Fifteen deer $(65 \%)$ were migratory and 8 deer $(35 \%)$ were non-migratory (Table 1$)$. All the deer that we monitored for $\geq 2$ years $(n=12)$ did not change their migration behavior between years. The proportions of migratory male and female deer were $50 \%$ and $71 \%$, respectively $(d f=1, P>0.05)$. Mean migration distance was $9.9 \pm 6.1 \mathrm{~km}$ (range $=3.2-22.9 \mathrm{~km})$, and there were no significant differences between sexes $(U=5.000, Z=$ $-1.876, P>0.05)$. Forty-seven percent $(n=7)$ of the migratory deer exhibited long-distance migration (i.e. $>10 \mathrm{~km}$ ), and 2 deer migrated $>20 \mathrm{~km}$. Migratory deer moved from Kirigamine Highland to contiguous areas with various directions during the winter, whereas 3 deer wintered at the foothills of Yatsugatake Mountains (Fig. 1). There were no significant differences in elevations of summer and winter home ranges between sexes for both migratory and non-migratory deer (migratory summer: $U=17.000, Z=-0.144, P>0.05$; migratory winter: $U=15.000, Z=-0.433, P>0.05$; non-migratory summer: $U=3.000, Z=-0.775, P>0.05$; non-migratory winter: $U=3.000, Z=-0.775, P>0.05)$. Although 1 of 15 migratory deer was an upward migrant (i.e. movement between higher elevation winter range and lower elevation summer range) and migrated $145 \mathrm{~m}$ higher winter home range, the overall migratory deer utilized significantly higher elevations during summer compared to winter $(Z=-2.953, P<0.01)$. Non-migratory deer did not shift elevations between summer and winter $(Z=$ -1.521, $P>0.05)$. During summer, there were no significant differences in elevation use between migratory and non-migratory deer $(U=47.000, Z=-0.388$, $P>0.05)$. All deer utilized $>1,500 \mathrm{~m}$ a.s.l. during the summer. Of the 7 non-migratory deer that stayed at Kirigamine Highland, 6 deer's summer home range overlapped with migratory deer $(5.0 \pm 3.3$ migratory deer/non-migratory deer, range $=1-10, n=7$ ).

All but 1 of the 15 migratory deer summered in Kirigamine. One male deer stayed at Mt. Futago, located at the east of Mt. Tateshina, $15 \mathrm{~km}$ west from Kirigamine Highland, during summer. Since the purpose of this study was to evaluate the onset of migration based on the climate of Kirigamine Highland, we excluded this deer from the evaluation of seasonal migration and climate. We documented the 39 seasonal movements during 4 migratory periods: autumn $2008(n=11)$, spring 2009 $(n=10)$, autumn $2009(n=10)$ and spring $2010(n=8)$.

\section{Dispersal}

All of the 4 male fawns dispersed (Table 2). When the dispersal began, the deer age ranged from 12 to 23month-old. Three deer dispersed during May and June, while 1 deer dispersed during November. Distance of dispersal ranged from 3.0 to $40.3 \mathrm{~km}$. All the deer moved eastwards during dispersal. From visual observation and radio-tracking, 2 male fawns (2D and $8 \mathrm{M}$ ) stayed with their mother's group (VHF collared female) before dispersal. Both of these fawns exhibited nonmigratory movement after dispersal, which was the same as their mother.

Table 1. Numbers of migratory and non-migratory sika deer, migration distance, and elevations of seasonal home ranges of sika deer captured in Kirigamine Highland, Nagano, central Japan, 2008-2010, with $\geq 8$ months tracking

\begin{tabular}{|c|c|c|c|c|c|c|}
\hline & \multicolumn{3}{|c|}{ Migratory } & \multicolumn{3}{|c|}{ Non-migratory } \\
\hline & Male & Female & Total & Male $^{\mathrm{a}}$ & Female & Total \\
\hline Numbers of deer & 3 & 12 & 15 & 3 & 5 & 8 \\
\hline Migration distance $(\mathrm{km})$ & $16.0 \pm 6.4$ & $8.4 \pm 5.1$ & $9.9 \pm 6.1$ & - & - & - \\
\hline \multicolumn{7}{|l|}{ Elevation (m) } \\
\hline Summer & $1,505 \pm 355$ & $1,548 \pm 104$ & $1,539 \pm 164$ & $1,620 \pm-$ & $1,552 \pm 135$ & $1,572 \pm 117$ \\
\hline Winter & $1,298 \pm 323$ & $1,318 \pm 172$ & $1,314 \pm 196$ & $1,471 \pm-$ & $1,510 \pm 69$ & $1,499 \pm 66$ \\
\hline
\end{tabular}

${ }^{a}$ Non-migratory male that stayed at the area $40 \mathrm{~km}$ away from Kirigamine Highland was excluded from the elevation analysis. 


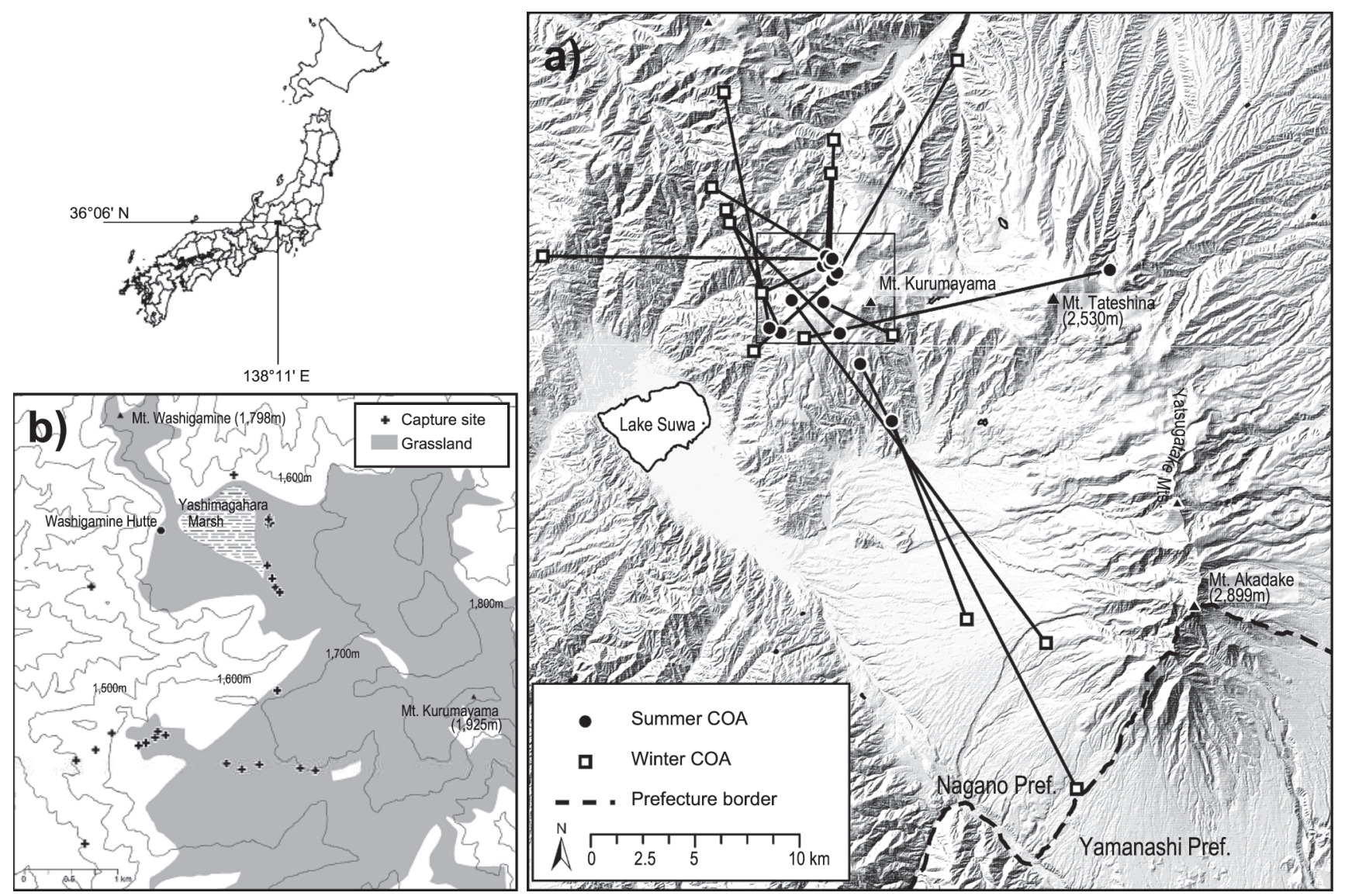

Fig. 1. Summer and winter center of activity (COA) with connected line, which indicates distance and direction for 15 (12 females and 3 males) migratory sika deer, 2008-2011 (a).Capture sites of 27 sika deer in Kirigamine Highland, Nagano, central Japan, 2008-2010 and location of Washigamine Hütte, where daily temperatures and snow depths were measured (b). The area of Fig (b) is outlined as a square in Fig (a).

Table 2. Dispersal by juvenile male sika deer captured in Kirigamine Highland, Nagano, central Japan, 2008

\begin{tabular}{|c|c|c|c|c|c|c|}
\hline \multirow{2}{*}{ Deer ID } & \multicolumn{2}{|c|}{ Age (months) } & \multirow{2}{*}{ Dispersal Date $^{a}$} & \multirow{2}{*}{$\begin{array}{l}\text { Dispersal Distance } \\
(\mathrm{km})\end{array}$} & \multirow{2}{*}{$\begin{array}{c}\text { Dispersal Direction } \\
\left(^{\circ}\right)\end{array}$} & \multirow{2}{*}{$\begin{array}{c}\text { Postdispersal } \\
\text { Migration Pattern }\end{array}$} \\
\hline & Capture & Dispersal & & & & \\
\hline $2 \mathrm{D}$ & 10 & 23 & 14 May 2009 & 40.3 & 117 & Non-migratory \\
\hline $8 \mathrm{M}$ & 11 & 17 & 13 Nov 2008 & 4.3 & 80 & Non-migratory \\
\hline $15 \mathrm{H}$ & 11 & 12 & 16 Jun 2008 & 34.6 & 125 & Unkown $^{\mathrm{b}}$ \\
\hline $18 \mathrm{M}$ & 11 & 12 & 18 Jun 2008 & 3.0 & 112 & Migratory \\
\hline
\end{tabular}

${ }^{a}$ The date when dispersal began.

${ }^{\mathrm{b}}$ This deer had been lost due to VHF collar malfunction from July 2008, but was killed and the collar was retrieved on Aug 2009.

\section{Site fidelity}

All the deer that we monitored for $\geq 2$ seasons (summer: $n=15$; winter: $n=13$ ) had overlapping summer and winter home range. Since the distance between the center of activity in successive years did not differ among migratory and non-migratory deer (summer: $U=65.000$, $Z=-0.277, P>0.05$; winter: $U=14.000, Z=-0.169$, $P>0.05$ ), we pooled the data to compare the site fidelity between summer and winter home range. Distance between the center of activity of successive summer and winter home range was greater in winter $(768 \pm 623 \mathrm{~m}$, $n=13)$ than in summer $(403 \pm 536 \mathrm{~m}, n=27)$, which indicates high fidelity to summer home range $(U=84.0$, $Z=-2.122, P<0.05)$.

\section{Autumn migration}

We observed 12 and 10 migratory deer during autumn 2008 and autumn 2009, respectively. We were unable to 
Table 3. Median date of migration during 7 migratory periods for sika deer captured in Kirigamine Highland, Nagano, central Japan, 2008-2011. Autumn and spring migration date is the departure and arrival date of the summer home range, respectively

\begin{tabular}{lrlc}
\hline Migratory period & $n$ & Median & Range \\
\hline Spring 2008 & 1 & 4 May & - \\
Autumn 2008 & 12 & $22 \mathrm{Nov}$ & $27 \mathrm{Aug}-1 \mathrm{Jan}$ \\
Spring 2009 & 11 & $17 \mathrm{Apr}$ & $22 \mathrm{Mar}-13 \mathrm{May}$ \\
Autumn 2009 & 11 & $8 \mathrm{Nov}$ & $30 \mathrm{Aug}-31 \mathrm{Dec}$ \\
Spring 2010 & 9 & $9 \mathrm{Apr}$ & $3 \mathrm{Mar}-16 \mathrm{May}$ \\
Autumn 2010 & 2 & $2 \mathrm{Dec}$ & $23 \mathrm{Nov}-12 \mathrm{Dec}$ \\
Spring 2011 & 2 & $4 \mathrm{May}$ & $12 \mathrm{Apr}-27 \mathrm{May}$ \\
\hline
\end{tabular}

determine the departure date of 1 deer during autumn 2008. Timing of the first occurrence of snow depth $>20$ cm was 10 January during 2008-2009 and 19 December during 2009-2010. The number of days with snow depth $>40 \mathrm{~cm}$ was 22 days and 60 days during 2008-2009 and 2009-2010, respectively. Median date of autumn migration occurred in November for both years, ranging from 27 August-1 January (127 days) and 30 August-31 December (123 days), respectively (Table 3). Autumn migration of the deer corresponded to snow accumulation (Fig. 2). The proportion of the deer migrated before the first snow depth reached $20 \mathrm{~cm}$ was $100 \%$ $(n=11)$ and $80 \%(n=10)$ in 2008 and 2009 , respectively. During autumn 2009, two deer migrated after the snow depth reached $>40 \mathrm{~cm}$. Two same deer migrated before snowfall when daily temperatures were $>10^{\circ} \mathrm{C}$ during the 2 consecutive years. Although $82 \%(n=9)$ of the migration events occurred after the daily temperatures $<0^{\circ} \mathrm{C}$ persisted for more than 3 days in $2008,50 \%$ $(n=5)$ of the migration events occurred in such temperatures in 2009.

\section{Spring migration}

We observed 10 and 8 migratory deer during spring 2009 and spring 2010, respectively. We were unable to locate 2 deer due to GPS collar and radiocollar malfunction during the winter of 2008-2009. Two deer were killed by hunting during the winter of 2009-2010. Median date of spring migration occurred in April for both 2009 and 2010, ranging from 22 March-13 May (52 days) and 3 March-16 May (74 days), respectively (Table 2). Proportion of the deer migrated after snow cover disappeared in Kirigamine Highland was 50\% and $75 \%$ in 2009 and 2010, respectively (Fig. 2). The remaining deer migrated during periods when snow depths were rapidly decreasing. All the spring migra-

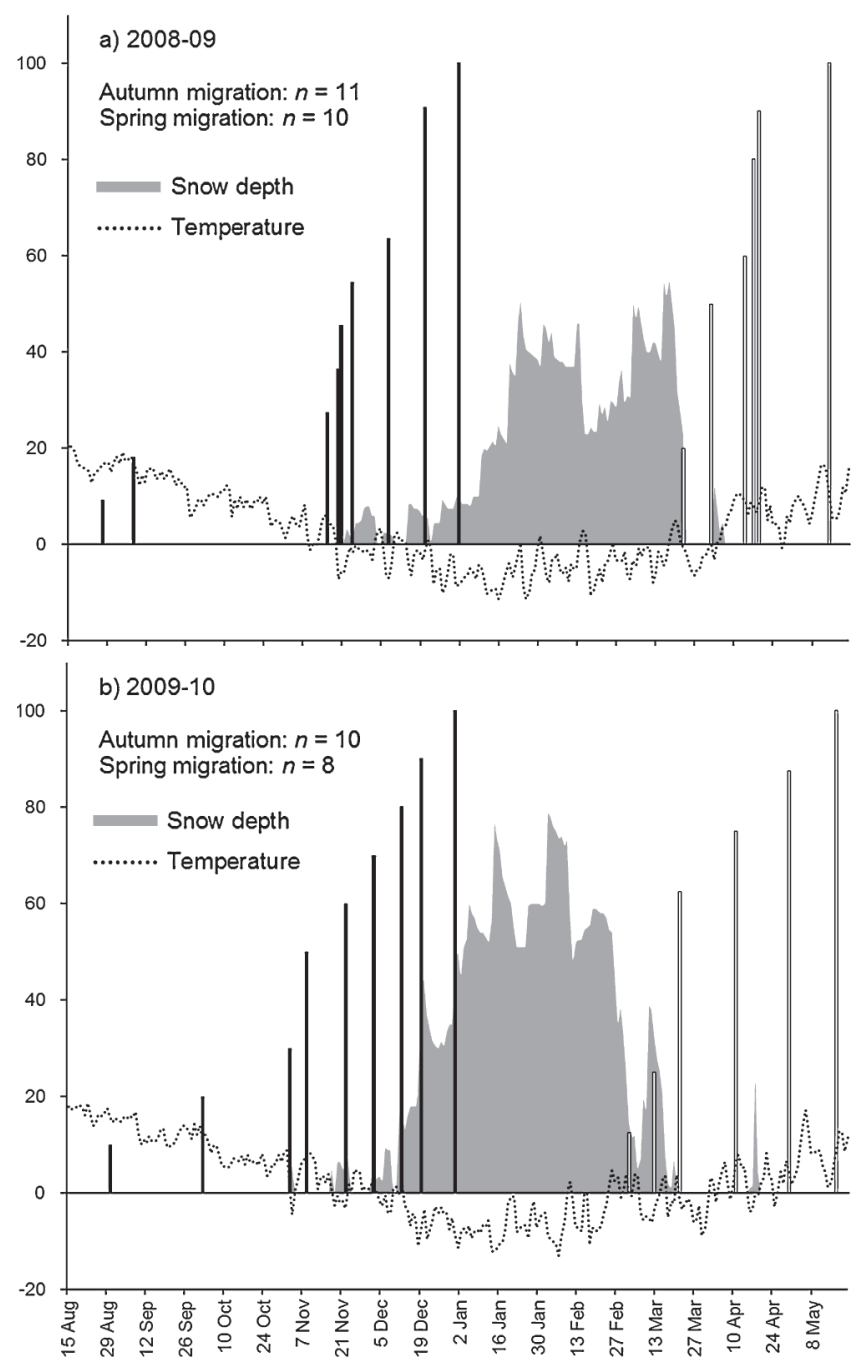

Fig. 2. Autumn migration events (\%, solid bars: autumn migration, open bars: spring migration), mean daily temperatures $\left({ }^{\circ} \mathrm{C}\right.$, dotted lines), and snow depths (cm, shaded region) in Kirigamine Highland, Nagano, central Japan, 2008-2010. The Y-axis is shared by all 3 variables. Migration events represent the cumulative percentage of migrating individuals during the season.

tions occurred after the daily temperatures $>0{ }^{\circ} \mathrm{C}$ persisted for more than 3 days in 2008 and 2009.

\section{Discussion}

\section{Migration pattern}

This is the first study to our knowledge to describe the migration pattern of sika deer from $>20$ individuals including males and females in Japan. Migratory and non-migratory deer were observed in Kirigamine Highland regardless of sex. Sixty-five percent $(n=15)$ of the deer were migratory, and most deer migrated between high-elevation summer range and low-elevation winter 
range. Few studies have indicated partial migration of sika deer in Japan (Maruyama 1981; Takatsuki et al. 2000; Igota et al. 2004), whereas it has been well documented in other cervid populations (e.g., Kufeld et al. 1989; Mysterud 1999; Sabine et al. 2002; Cagnacci et al. 2011). Sika deer in our study did not change their migration pattern throughout the study period regardless of the winter conditions. However, 1 or 2 migratory periods used in our study must be taken into account when considering migration pattern because long-term study can lead to improved estimates of population structure (Fieberg et al. 2008).

In Kirigamine Highland, both migratory and nonmigratory deer utilized similar, relatively high, elevations during summer. Furthermore, the summer home range of most non-migratory deer overlapped with migratory deer. Mixed-migration pattern of deer in the same area has been explained by variability in climate, especially snow depth (Nicholson et al. 1997; Brinkman et al. 2005; Ramanzin et al. 2007). Snow depth vary by slope aspects, and Borkowski et al. (1996) reported that sika deer shift the utilization of slope aspects when snow deepens. Kirigamine Highland holds various aspects and slope gradients that will certainly provide various snow cover pattern. Such variable winter conditions probably allowed the non-migratory deer to winter in Kirigamine Highland. However, it is likely that the longer period of snow accumulation $>20 \mathrm{~cm}(2008-2009=72$ days; $2009-2010=83$ days) forced many deer in Kirigamine Highland to migrate into less snowy areas.

Migration distance of sika deer in Kirigamine Highland $(9.9 \mathrm{~km}$, range $=3.2-22.9 \mathrm{~km})$ was similar to previously reported for sika deer population in central Japan (Honma $1995[11.1 \mathrm{~km}$, range $=8.2-14.4 \mathrm{~km}]$; Takii et al. $2012[15.9 \mathrm{~km}$, range $=2.5-31.9 \mathrm{~km}]$ ), but was shorter than those for sika deer population in eastern Hokkaido (Uno and Kaji 2000 [19.9 km, range $=2.5-$ $42.0 \mathrm{~km}$ ]; Igota et al. $2004[35.1 \mathrm{~km}$, range $=7.2-$ $101.7 \mathrm{~km}]$ ). Sika deer in Hokkaido exhibits large-scale seasonal migrations since the wintering area for sika deer is restricted to a few areas due to heavy snow and limited coniferous forests (Igota et al. 2009). Compared to Hokkaido, heavy-snow region is limited to the areas along the Sea of Japan and sub-alpine to alpine range in central Japan (Japan Meteorological Agency 2002). The snow depth varies considerably along altitudinal gradient even in the surrounding areas of Kirigamine Highland. For instance, during 2008-2011, the maximum snow depth at Washigamine Hütte ranged 56-108 cm, whereas at meteorological station of Suwa $\left(36^{\circ} 03^{\prime} \mathrm{N}, 138^{\circ} 07^{\prime} \mathrm{E}\right.$; $760 \mathrm{~m}$ a.s.1.), $10.3 \mathrm{~km}$ southwest of Washigamine Hütte, maximum snow depth ranged only 11-22 cm (Meteorological data of Nagano Prefecture, Nagano Local Meteorological Observatory, Nagano). Thus, it is likely that sika deer need not move such long distance to seek for wintering areas in central Japan. On the contrary, 2 deer migrated $>20 \mathrm{~km}$ (adult female: $20.5 \mathrm{~km}$; juvenile male: $22.9 \mathrm{~km}$ ) between Kirigamine Highland and the foothills of Yatsugatake Mountains. Few studies have reported such long distance migration of sika deer in central Japan (Izumiyama et al. 2009; Takii et al. 2012). Although explanations for these deer to migrate $>20 \mathrm{~km}$ is speculative, factors other than climate should be associated with these movements.

One upward migrant (adult female) migrated to $145 \mathrm{~m}$ higher elevation winter range. Such upward migration is uncommon in cervids and has been reported by few studies, and it is regarded as a response to snow cover pattern or human activities (Igota et al. 2004; Pépin et al. 2008; Takii et al. 2012). Given that this deer wintered along the south-facing road that was closed for traffic during winter, and evergreen grasses were available during the winter (personal observation, Akiko Takii, Interdisciplinary Graduate School of Science and Technology, Shinshu University), she maybe wintered in higher elevation because the area was less disturbed with available forage. Furthermore, since the summer home range of this deer overlapped with another female deer (downward migrant), upward migration in our study may not relate to specific area, but more to individual variability.

Although the deer utilized about the same summer and winter home range, fidelity to summer home range was stronger than fidelity to winter home range, which corresponds to the earlier studies of sika deer (Uno and Kaji 2000; Igota et al. 2004) and other cervids (Tierson et al. 1985; Nicholson et al. 1997; Van Deelen et al. 1998). In addition, presumably the deer that wintered in 2 distinct areas is the indication of the lower fidelity to winter home range. Tierson et al. (1985) assumed that range fidelity was affected by variations in snow depth and winter logging. The less fidelity to winter range in Kirigamine Highland may have been due to the variation in the first occurrence of snow depth $>20 \mathrm{~cm}$, and the number of days with snow depth $>40 \mathrm{~cm}$ between years.

\section{Dispersal}

Few studies have reported on dispersal of sika deer 
in Japan (Maruyama 1981; Yamazaki and Furubayashi 1995). We found that the age, date and distance of dispersal varied among individuals, but this may be due to small sample size. Although Yamazaki and Furubayashi (1995) reported 1 juvenile male sika deer dispersed at 2.5-year-old, we found the juvenile males disperse at younger age. In white-tailed deer, $\geq 50 \%$ of juvenile males disperse, but the age of dispersal ranges from 10 to 30 months (DeYoung 2011). Two male deer, which their mother was also radio-tracked, exhibited non-migratory movement pattern that was the same as their mother. Our study is the first to report the pre and postdispersal movements of fawn along with their mother's movement for sika deer. Further study with sufficient sample size is needed for the interpretation of dispersal movement for sika deer.

\section{Seasonal migration}

Autumn migration of sika deer in our study was associated with snow accumulation and freezing temperatures. During the two years, autumn migration occurred before the snow depth reached $20 \mathrm{~cm}$, which was far below the point $(50 \mathrm{~cm})$ at which has been known to avoid the locomotion of sika deer (Maruyama 1981; Takatsuki 1992). Relatively high percentage of autumn migration occurred after the daily temperature $<0{ }^{\circ} \mathrm{C}$ persisted for more than 3 days. Our results were consistent with previous studies that have demonstrated severe winter weather (i.e. deep snow and freezing temperatures) affects the onset of autumn migration (Nelson 1995; Nicholson et al. 1997; Mysterud 1999; Sabine et al. 2002; Brinkman et al. 2005; Grovenberg et al. 2009; Monteith et al. 2011). On the contrary, in eastern Hokkaido, snow cover did not initiate autumn migration of sika deer (Igota et al. 2009). Some studies also report similar results to our study that initiation of migration was associated with the shallower snow depths (Nelson 1995; Uno and Kaji 2000; Sabine et al. 2002; Brinkman et al. 2005; Fieberg et al. 2008). Deep snow limits the movement and increases energy expenditure of deer (Parker et al. 1984), and snow cover reduces remarkable amount of forage availability during winter (Schwartz and Hobbs 1985). Furthermore, heat loss will be greater in low ambient temperatures (Moen 1968), especially during winter when forage quality and quantity reduces. Therefore, it is likely that deer migrate before deep snow accumulates in Kirigamine Highland to minimize energy costs.

Meanwhile, 2 deer departed Kirigamine Highland during late summer-early autumn (27 Aug-2 Oct) and descended to lower elevations. Obviously, autumn migration of these deer was independent of snow. Because Kirigamine Highland is located at high-elevation, growth period of plants is shorter compared to lower elevation area. Senescence of plants will lead to decline in crude protein (Albon and Langvatn 1992) and biomass (Hunter and Grant 1971). Thus, it appears that one reason for these deer to arrive earlier at winter range was to seek for better quality forage. However, this explanation is insufficient because most of the migratory deer stayed in Kirigamine Highland until late autumn or early winter. Although further analysis should be made, this may be explained by the recent founding of Monteith et al. (2011), who studied mule deer population for 11 years, that timing of autumn migration vary substantially among individual deer, namely age and nutritional condition.

In accordance with previous findings (Nelson 1995; Uno and Kaji 2000; Sabine et al. 2002; Igota et al. 2004; Brinkman et al. 2005; Ramanzin et al. 2007), spring migration occurred when either snow had completely disappeared or during the snow melted rapidly, and was associated with increasing temperatures. We also found the range of spring migration (52-74 days) was smaller than autumn migration (123-127 days). Our results were in agreement with Sabine et al. (2002) that found the similar migration range in white-tailed deer, and explained that spring migration was a quick response to bare ground appearance. Meanwhile, since growth of plants arrests during winter, the longer deer stay in the winter range, the less forage availability becomes. Monteith et al. (2011) described that it is beneficial for deer to leave the winter range as early as possible in order to seek for better forage, which may explain our results.

Deer migrate to higher elevation during spring to seek for higher quality of forage at early phenological stages (Albon and Langvatn 1992). Sakuragi et al. (2003) showed that north migrants feed on high quality forage compared to non-migrants during summer. Although we do not have data on forage quality, spring migration may be attributed to the extensive grasslands in Kirigamine Highland. Sika deer in northern Japan are highly dependent on graminoids and identified as grazer (Takatsuki 2009). Furthermore, strong fidelity to summer ranges indicates high fidelity to breeding sites for females. Because reproduction (i.e. pregnancy and lactation) is energetically expensive (Oftedal 1985), deer needs to feed on high quality diets during spring to autumn. Thus, extensive grassland will obviously provide favorable 
habitat for sika deer during summer.

However, why the deer have not been common in Kirigamine Highland until the early-1990s (Kishimoto et al. 2010)? Mysterud et al. (2011) has recently proposed the competition avoidance hypothesis that "deer migrate uphill in summer to escape competition due to the high density in winter areas", and mentioned that duration of migration will be short in that case. Although we do not have the exact date of migration for most deer because we did not locate the VHF collared deer every day, two upward migrant fitted with GPS collar completed spring migration within 1 day. The sample size maybe too small, but given the increase in number of deer harvested in county of Suwa (953 deer and 2,109 deer harvested in 2005 and 2009: Nagano Prefecture 2011), which indicate the increase in deer density, this hypothesis might provide explanation for deer migration in Kirigamine Highland. Future work of altitudinal migration of sika deer should therefore consider both duration of migration and effect of plant phenology to evaluate the migration trait in a specific area.

Acknowledgments: Part of the capture and radio-tracking of deer for this study was commissioned by Nagano Prefecture Suwa Regional Office. We are especially grateful for T. Mochizuki for his cooperation in capturing the deer. We thank two anonymous reviewers for providing valuable comments to improve this paper. We also thank the students of Shinshu University for their assistance in capturing the deer.

\section{References}

Albon, S. D. and Langvatn, R. 1992. Plant phenology and the benefits of migration in a temperate ungulate. Oikos 65: 502-513.

Ball, J. P., Nordengren, C. and Wallin, K. 2001. Partial migration by large ungulates: characteristics of seasonal moose (Alces alces) ranges in northern Sweden. Wildlife Biology 7: 39-47.

Borkowski, J., Habuto, H. and Furubayashi, K. 1996. Effect of snow cover on the distribution of non-migratory sika deer of Mt. Tanzawa, Japan. Journal of Forest Research 1: 9-11.

Brinkman, T. J., Deperno, C. S., Jenks, J. A., Haroldson, B. S. and Osborn, R. G. 2005. Movement of female white-tailed deer: effects of climate and intensive row-crop agriculture. Journal of Wildlife Management 69: 1099-1111.

Cagnacci, F., Focardi, S., Heurich, M., Stache, A., Hewison, A. M., Morellet, N., Kjellander, P., Linnell, J. C., Mysterud, A., Neteler, M., Delucchi, L., Ossi, F. and Urbano, F. 2011. Partial migration in roe deer: migratory and resident tactics are end points of a behavioural gradient determined by ecological factors. Oikos 120: $1790-1802$.

DeYoung, C. A. 2011. Population dynamics. In (D. G. Hewitt, ed.) Biology and Management of White-Tailed Deer, pp. 147-180. CRC Press, Boca Raton.
Dingle, H. and Drake, V. A. 2007. What is migration? BioScience 57: 113-121.

ESRI 1996. ArcView Spatial Analyst. Environmental Systems Research Institute, Redlands, California.

Fieberg, J., Kuehn, D. W. and DelGiudice, G. D. 2008. Understanding variation in autumn migration of northern white-tailed deer by long-term study. Journal of Mammalogy 89: 1529-1539.

Grovenberg, T. W., Jenks, J. A., Klaver, R. W., Swanson, C. C., Jacques, C. N. and Todey, D. 2009. Seasonal movements and home ranges of white-tailed deer in north-central South Dakota. Canadian Journal of Zoology 87: 876-885.

Hayne, D. W. 1949. Calculation of size of home range. Journal of Mammalogy 30: 1-18.

Hebblewhite, M., Merrill, E. and McDermid, G. 2008. A multi-scale test of the forage maturation hypothesis in a partially migratory ungulate population. Ecological Monographs 78: 141-166.

Honma, K. 1995. Movement Patterns and Habitat Use of Sika Deer (Cervus nippon) in Oku-Nikko and Ashio Area. Master's Thesis, Graduate School of Education, Joetsu University of Education, 60 pp. (in Japanese).

Hosoda, H. and Taguchi, M. 2009. Climatic characteristics in and around Yashimagahara moor, Kirigamine, Nagano. Journal of Geographic Society of Hosei University 41: 3-20 (in Japanese).

Hunter, R. S. and Grant, S. A. 1971. The effects of altitude on grass growth in east Scotland. Journal of Applied Ecology 8: 1-19.

Igota, H., Sakuragi, M., Uno, H., Kaji, K., Kaneko, M., Akamatsu, R. and Maekawa, K. 2004. Seasonal migration patterns of female sika deer in eastern Hokkaido, Japan. Ecological Research 19: 169-178.

Igota, H., Sakuragi, M. and Uno, H. 2009. Seasonal migration of sika deer on Hokkaido Island, Japan. In (D. R. McCullough, S. Takatsuki and K. Kaji, eds.) Sika Deer, pp. 251-272. Springer, Tokyo.

Izumiyama, S. and Mochizuki, T. 2008. Seasonal range use of sika deer which inhabits the sub-alpine zone in the Southern Japan Alps. Bulletin of Shinshu University AFC 6: 25-32 (in Japanese with English summary).

Izumiyama, S., Mochizuki, T. and Takii, A. 2009. GPS tracking of sika deer which inhabits the sub-alpine zone in the Southern Japan Alps. Bulletin of Shinshu University AFC 7: 63-71 (in Japanese with English abstract).

Japan Meteorological Agency. 2002. Mesh Climatic Data 2000. Tokyo (in CD-ROM).

Kamei, T., Takeda, K., Izumiyama, S. and Oshima, K. 2010. The effect of hunting on the behavior and habitat utilization of sika deer (Cervus nippon). Mammal Study 35: 235-241.

Kishimoto, R., Aizawa, H., Yoshioka, M., Ishida, Y., Mitsui, K. and Suga, S. 2010. Population dynamics of sika deer Cervus nippon monitored by spotlight-census in Kirigamine, central Japan. Bulletin of Nagano Environmental Conservation Research Institute 6: 13-16 (in Japanese).

Kufeld, R. C., Bowden, D. C. and Schrupp, D. L. 1989. Distribution and movements of female mule deer in the Rocky Mountain foothills. Journal of Wildlife Management 53: 871-877.

Maruyama, N. 1981. A study of the seasonal movements and aggregation patterns of sika deer. Bulletin of Faculty of Agriculture, Tokyo University of Agriculture and Technology 23: 1-85 (in Japanese with English summary).

Ministry of the Environment 1997. Japan Integrated Biodiversity Information System (J-IBIS). http://www.biodic.go.jp/index e.html.

Moen, A. N. 1968. Surface temperatures and radiant heat loss from white-tailed deer. Journal of Wildlife Management 32: 338-344.

Monteith, K. L., Bleich, V. C., Stephenson, T. S., Pierce, B. M., 
Conner, M. M., Klaver, R. W. and Bowyer, R. T. 2011. Timing of seasonal migration in mule deer: effects of climate, plant phenology, and life-history characteristics. Ecosphere 2: 1-34.

Mysterud, A. 1999. Seasonal migration pattern and home range of roe deer (Capreolus capreolus) in an altitudinal gradient in southern Norway. Journal of Zoology 247: 479-486.

Mysterud, A., Loe, L. E., Zimmermann, B., Bischof, R., Veiberg, V. and Meisingset, E. 2011. Partial migration in expanding red deer populations at northern latitudes - a role for density dependence? Oikos 120: 1817-1825.

Nagano Prefecture 2011. The Third Plan for Conservation and Management of Sika Deer in Nagano Prefecture. Nagano Prefecture Department of Forestry, Nagano, 48 pp. (in Japanese).

Nagata, K. 2005. Home range characteristic of sika deer in Fudakake of Tanzawa Mountains. Honyurui Kagaku [Mammalian Science] 45: 25-33 (in Japanese with English abstract).

Nelson, M. E. 1995. Winter range arrival and departure of whitetailed deer in northeastern Minnesota. Canadian Journal of Zoology 73: 1069-1076.

Nicholson, M. C., Bowyer, R. T. and Kie, J. G. 1997. Habitat selection and survival of mule deer: tradeoffs associated with migration. Journal of Mammalogy 78: 483-504.

Nishimura, K., Soga, Y., Tsuda, S., Saijoh, Y. and Mo, W. 1997. Altitudinal variation in the species composition of main grasses in the Kirigamine subalpine grassland, central Japan. Grassland Science 42: 324-334 (in Japanese with English abstract).

Oftedal, O. T. 1985. Pregnancy and lactation. In (R. J. Hudson and R. G. White, eds.) Bioenergetics of Wild Herbivores, pp. 215-238. CRC Press, Boca Raton, Florida.

Ozeki, M., Hotta, M., Kawakami, M. and Otsuka, K. 2006. Vegetation change in the Kirigamine grassland. Bulletin of Nagano Environmental Conservation Research Institute Research Project 4: 17-24 (in Japanese).

Parker, K. L., Robbins, C. T. and Hanley, T. A. 1984. Energy expenditures for locomotion by mule deer and elk. Journal of Wildlife Management 48: 474-488.

Pépin, D., Adrados, C., Janeau, G., Joachim, J. and Mann, C. 2008. Individual variation in migratory and exploratory movements and habitat use by adult red deer (Cervus elaphus L.) in a mountainous temperate forest. Ecological Research 23: 1005-1013.

Ramanzin, M., Sturaro, E. and Zanon, D. 2007. Seasonal migration and home range of roe deer (Capreolus capreolus) in the Italian eastern Alps. Canadian Journal of Zoology 85: 280-289.

Sabine, D. L., Morrison, S. F., Whitlaw, H. A., Ballard, W. B., Forbes, G. J. and Bowman, J. 2002. Migration behavior of white-tailed deer under varying winter climate regimes in New Brunswick. Journal of Wildlife Management 66: 718-728.

Sakuragi, M., Igota, H., Uno, H., Kaji, K., Kaneko, M., Akamatsu, R. and Maekawa, K. 2003. Benefit of migration in a female sika deer population in eastern Hokkaido, Japan. Ecological Research 18: 347-354.

Sakuragi, M., Igota, H., Uno, H., Kaji, K., Kaneko, M., Akamatsu, R. and Maekawa, K. 2004. Female sika deer fidelity to migration route and seasonal ranges in eastern Hokkaido, Japan. Mammal Study 29: 113-118.

Schwartz, C. C. and Hobbs, N. T. 1985. Forage and range evaluation. In (R. J. Hudson and R. G. White, eds.) Bioenergetics of Wild Herbivores, pp. 27-51. CRC Press, Boca Raton.

Suwa Educational Association 1981. Natural History of Suwa: Wildlife Edition. Suwa Educational Association, Suwa, Nagano, 602 pp. (in Japanese).

Suzuki, H. and Yano, N. 1981. Vegetation of Kirigamine. The Board of Education of Suwa City, Suwa, Nagano, 246 pp. (in Japanese).

Takatsuki, S. 1992. Foot morphology and distribution of sika deer in relationship to snow depth in Japan. Ecological Research 7: 19-23.

Takatsuki, S. 2009. Geographical variations in food habits of sika deer: the northern grazer vs. the southern browser. In (D. R. McCullough, S. Takatsuki and K. Kaji, eds.) Sika Deer, pp. 231237. Springer, Tokyo.

Takatsuki, S., Suzuki, K. and Higashi, H. 2000. Seasonal elevational movements of sika deer on Mt. Goyo, northern Japan. Mammal Study 25: 107-114.

Takii, A., Izumiyama, S., Mochizuki, T., Okumura, T. and Sato, S. 2012. Seasonal migration of sika deer in the Oku-Chichibu Mountains, central Japan. Mammal Study 37: 127-137.

Tierson, W. C., Mattfeld, G. F., Sage, R. W. and Behrend, D. F. 1985. Seasonal movements and home ranges of white-tailed deer in the Adirondacks. Journal of Wildlife Management 49: 760-769.

Uno, H. and Kaji, K. 2000. Seasonal movements of female sika deer in eastern Hokkaio, Japan. Mammal Study 25: 49-57.

Van Deelen, T. R., Campa, H. III., Hamady, M. and Haufler, J. B. 1998. Migration and seasonal range dynamics of deer using adjacent deeryards in northern Michigan. The Journal of Wildlife Management 62: 205-213.

Yabe, T. and Takatsuki, S. 2009. Migratory and sedentary behavior patterns of sika deer in Honshu and Kyushu, Japan. In (D. R. McCullough, S. Takatsuki and K. Kaji, eds.) Sika Deer, pp. $273-$ 283. Springer, Tokyo.

Yamazaki, K. and Furubayashi, K. 1995. A record on dispersal of a young stag in western Tanzawa, central Japan. Journal of Japanese Forestry Society 77: 305-313 (in Japanese with English abstract).

Received 24 May 2012. Accepted 7 September 2012. 